\title{
Cellular Mechanisms for Increased Fetal Hemoglobin Production in Culture
}

\author{
EVIDENCE FOR CONTINUOUS COMMITMENT TO FETAL HEMOGLOBIN \\ PRODUCTION DURING BURST FORMATION
}

\author{
George J. Dover and Makio Ogawa, Howard Hughes Medical Institute, \\ Laboratory for Human Biochemical Genetics, Departments of Pediatrics and \\ Medicine, The Johns Hopkins University School of Medicine, Baltimore, \\ Maryland 21205; Veterans Administration Medical Center and \\ Department of Medicine, University of South Carolina, Charleston, \\ South Carolina 29403
}

\begin{abstract}
A B S T RACT Using microscopic immunodiffusion assays and microdensitometric analysis of pericellular immunoprecipitate, the percentage of nucleated erythrocytes containing fetal hemoglobin (FNRBC) and the mean picograms of fetal or adult hemoglobin per nucleated erythrocyte (picograms $\mathrm{HbF} / \mathrm{NRBC}$, picograms $\mathrm{HbA} / \mathrm{NRBC}$ ) were assayed in 14-d-old colonies (bursts) derived from peripheral blood erythroid progenitors. In the peripheral blood of 11 normal adults only $2.2 \pm 0.5 \%$ (mean $\pm \mathrm{SE}$ ) erythrocytes contained $\mathrm{HbF}$ whereas pooled bursts from the same subjects revealed a 13-fold increase in the percentage of FNRBC $(29.6 \pm 3.9 \%)$. In culture both the picograms $\mathrm{HbF} / \mathrm{NRBC}$ $(5.2 \pm 0.4)$ and the picograms HbA/NRBC $(27.7 \pm 1.5)$ are increased $\sim 20 \%$ above the mean in vivo levels in NRBC from normal bone marrow aspirates. Analysis of each of 58 bursts from one subject demonstrated that FNRBC are present in all bursts and range from 5.0 to $95.0 \%$ of the total NRBC per burst. The percent FNRBC in each burst was neither correlated with picograms $\mathrm{HbF} / \mathrm{NRBC}$ per burst nor with picograms $\mathrm{HbA} / \mathrm{NRBC}$ per burst. Individual subcolonies from one burst in each of two subjects demonstrated between 3 and $81 \%$ FNRBC.

These findings indicate that first, the increase in $\mathrm{HbF}$ production in culture is primarily due to increased production of the number of cells containing $\mathrm{HbF}$, not to increased picograms $\mathrm{HbF} / \mathrm{NRBC}$. Second, all
\end{abstract}

An abstract of this work was submitted to the 22nd Annual Meeting of the American Society of Hematology, December 1979, in Phoenix, Ariz.

Dr. Ogawa is a Medical Investigator for the Veteran's Administration. Dr. Dover is the recipient of Research Career Development Award K04 AM 00689-01.

Received for publication 25 August 1980. 14-d bursts contain some FNRBC. Third, just as seen in vivo, the picograms $\mathrm{HbF} /$ cell and the number of cells that contain $\mathrm{HbF}$ are independently regulated in culture. Fourth, commitment to produce $\mathrm{HbF}$ in vitro continues after subcolony formation in 14-d-old bursts. Augmentation of $\mathrm{HbF}$ production in culture therefore closely resembles that seen in acute erythroid stimulation in vivo.

\section{INTRODUCTION}

In normal adults peripheral blood erythropoietic progenitors, termed "burst-forming units" (BFU-E), ${ }^{1}$ produce in culture more fetal hemoglobin $(\mathrm{HbF})$ than erythroid precursors that develop in vivo (1). $\mathrm{HbF}$ production in vivo is increased by three independently regulated mechanisms; increased production of cells containing $\mathrm{HbF}$ ( $\mathrm{F}$ cells), increased production of $\mathrm{HbF} / \mathrm{F}$ cells, or preferential survival of $\mathrm{F}$ cells in comparison with erythrocytes that contain no $\mathrm{HbF}$ $(2,3)$. It is unknown to what extent these three different mechanisms contribute to increased $\mathrm{HbF}$ production in culture. Furthermore, it is unclear whether all peripheral blood BFU-E have the capacity to make $\mathrm{HbF}$ during differentiation. For example, while isoelectric focusing of hemoglobin indicates that $\mathrm{HbF}$ is present in all individual BFU-E colonies (bursts) (4), immunofluorescent staining of intact bursts with anti$\mathrm{HbF}$ antibody (5) and radioimmunoassays of hemo-

\footnotetext{
${ }^{1}$ Abbreviations used in this paper: BFU-E, burst-forming unit, erythroid; F cell, erythrocyte containing fetal hemoglobin; FNRBC, nucleated erythrocyte containing fetal hemoglobin; HbA, adult hemoglobin; HbF, fetal hemoglobin; NRBC, nucleated erythrocyte.
} 
lysates from individual bursts (6) indicate that only between 17 and $80 \%$ of bursts contain $\mathrm{HbF}$.

We have recently developed microdensitometric techniques for the quantitation of $\mathrm{HbF}$ or adult hemoglobin (HbA) in individual erythrocytes, reticulocytes, and nucleated erythrocytes (NRBC) (7). Application of the technique to NRBC derived from peripheral blood bursts should answer the following questions. Are NRBC containing $\mathrm{HbF}$ (FNRBC) present in all bursts? Is increased $\mathrm{HbF}$ production in culture due to increased production of FNRBC, increased amounts of $\mathrm{HbF} / \mathrm{FNRBC}$, or both? Is the production of $\mathrm{F}$ cells in culture regulated independently from the amount of $\mathrm{HbF} /$ cell as noted in vivo (3)? Answers to these questions should clarify at the cellular level the similarities and differences between $\mathrm{HbF}$ production in vivo and in culture.

\section{METHODS}

Erythropoietic cell culture. Mononuclear cells were isolated from heparinized peripheral blood of normal adult volunteers using modifications (8) of the Ficoll-Isopaque technique described by Boyum (9). Cell cultures were performed as previously reported (8) using slight modifications of the methylcellulose assay developed by Iscove et al. (10). In all cultures $1.0 \mathrm{IU} / \mathrm{ml}$ of Step III preparation of sheep plasma erythropoietin (Connaught Laboratories, Willowdale, Ontario, Canada) was used. On culture day 14, cells were harvested by diluting the culture mixture with isotonic

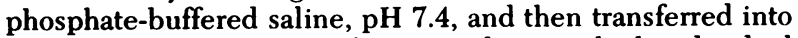
a 5-ml plastic centrifuge tube. In studies in which individual bursts or subcolonies from one burst were analyzed, each burst or subcolony was lifted separately from the culture dish using a 10- $\mu$ l Eppendorf pipette and placed in microcentrifuge tubes containing $\sim 250 \mu \mathrm{l}$ of $0.8 \%$ methylcellulose.

Single cell assay. Samples containing pooled bursts, an individual burst, or an individual subcolony were diluted with $1 \mathrm{ml}$ of phosphate-buffered saline and centrifuged at $8,000 \mathrm{~g}$ for $3 \mathrm{~min}$. The pellet of NRBC was washed three times with $1 \mathrm{ml}$ phosphate-buffered saline and centrifuged at $400 \mathrm{~g}$ for $30 \mathrm{~s}$. Washed NRBC were suspended in 20 to 40 $\mu \mathrm{l}$ of isotonic borate saline, $\mathrm{pH} 8.3$ (2). Aggregates of NRBC were disrupted by gentle tapping of the side of the tube. This cell suspension was divided into two equal aliquots. Each aliquot was added to a mixture containing $25 \mu \mathrm{l} 2.5 \%$ agarose, $5 \mu \mathrm{l}$ new methylene blue, and $25 \mu \mathrm{l}$ of antibody to either human $\mathrm{HbF}$ or $\mathrm{HbA}$. The suspension of NRBC in agarose gel was placed on microscopic slides (2), and following lysis of the NRBC with lysolecithin those cells with a HbFanti-HbF or HbA-anti-HbA pericellular immunoprecipitate reaction were enumerated $(2,7)$.

At least $3 \times 10^{6}$ cells were recovered after wash from pooled burst samples. In individual burst samples, between 1,000 and 3,000 cells were recovered for each assay. Between 50 and 250 cells were present in individual subcolonies. In all assays, between 85 and $95 \%$ of the NRBC reacted with anti-HbA (mean, $90.1 \pm 3.0 \%$ ). In pooled burst samples, the percentage of NRBC reacting with anti-HbA corresponded exactly to the percentage of washed NRBC staining with benzidine, indicating that all NRBC assayed contained $\mathrm{HbA}$ and that 5-15\% NRBC may have lysed before or during the washing procedure. In view of this, the percentage of FNRBC was expressed as the percentage of cells reacting with anti-HbF divided by the percentage of cells reacting with anti-HbA.
Using a recently devised microdensitometric method (7), the picograms of $\mathrm{HbF}$ or $\mathrm{HbA}$ in individual NRBC were quantitated. For each sample at least 100 NRBC containing $\mathrm{HbF}$ or $\mathrm{HbA}$ were examined and values were expressed as picograms $\mathrm{Hb} / \mathrm{NRBC}($ mean $\pm \mathrm{SD})$.

\section{RESULTS}

Pooled bursts. Analysis of pooled bursts from each of 11 normal subjects demonstrated that the mean percentage of FNRBC found in culture is 13.5-fold greater than the mean percentage of $F$ cells produced in vivo (Table $\mathrm{I})$. This increase in $\mathrm{F}$-cell production beyond the normal in vivo range, 0.5 to $7.5 \%$ (11), is similar to the previously reported 10 - to 18 -fold increase in lysate $\mathrm{HbF}$ synthesis in culture $(12,13)$. There was no correlation between peripheral blood F-cell levels and percentage of FNRBC produced in culture $(P=0.50) .^{2}$

In a separate study we noted that $\mathrm{HbF}$ production in vivo is essentially complete early in normal erythroid development, i.e., the picograms of $\mathrm{HbF}$ in mature peripheral blood erythrocytes is not significantly different from $\mathrm{HbF}$ found in nucleated erythroid precursors in bone marrow aspirates (7). Therefore a comparison in normal adults between mean cellular $\mathrm{HbF}$ content in NRBC from erythropoietic bursts and mean $\mathrm{HbF}$ levels in peripheral blood erythrocytes should determine whether or not the amount of $\mathrm{HbF} / \mathrm{NRBC}$ in culture is increased beyond in vivo NRBC levels. In five subjects (Table I, subjects $1,2,3$, 4 , and 7), the mean picograms HbF/NRBC, $5.3 \pm 0.6$ pg (mean $\pm \mathrm{SE})$, was $23 \%$ greater than the mean $\mathrm{F}$-cell levels $(P=0.05)$. In bone marrow aspirates from five normal subjects previously studied, $\mathrm{HbF} / \mathrm{NRBC}$ was $4.3 \pm 0.2 \mathrm{pg}$ and $\mathrm{HbA} / \mathrm{NRBC}$ was $22.0 \pm 0.7 \mathrm{pg}$ (7). These in vivo values are $20 \%$ less for $\mathrm{HbF}(P=0.04)$ and $25 \%$ less for $\mathrm{HbA}(P>0.01)$ than the mean picograms $\mathrm{HbF} /$ NRBC and picograms $\mathrm{HbA} / \mathrm{NRBC}$ values found in culture for all 10 subjects in Table I. Since there is little difference in the relative increase in the cellular levels of $\mathrm{HbF}$ and $\mathrm{HbA}$, the marked increase in $\mathrm{HbF}$ production in culture is due primarily to the 13-fold increase in the numbers of cells containing $\mathrm{HbF}$. Among the 10 subjects studied there was no correlation in culture between percentage of FNRBC and picograms of $\mathrm{HbF} / \mathrm{NRBC}(P=0.1)$.

Individual bursts. In 108 individual bursts from three subjects and 58 individual bursts from subject 1 , FNRBC were found in every burst. In subject 1 the mean percentage of FNRBC per burst was $48.7 \%$, a value that closely parallels the $43.7 \%$ FNRBC value derived from pooled bursts from the same culture (see Fig. 1 and Table I, subject $1 \mathrm{~b}$ ). In subject 1 the

${ }^{2}$ All probability statistics in this paper were performed using the Mann-Whitney or Spearman's Rank method when comparing samples with unequal variances, and the Student $t$ test when comparing samples with equal variances. 
TABLE I

Single-Cell Analysis of Pooled 14-d Bursts from Each of 11 Normal Subjects

\begin{tabular}{|c|c|c|c|c|c|}
\hline \multirow[b]{2}{*}{ Subject } & \multicolumn{2}{|c|}{ Percentage of $F$ cells } & \multicolumn{3}{|c|}{ Picograms Hb/cell } \\
\hline & $\begin{array}{c}\text { Burst } \\
\text { FNRBC \% }\end{array}$ & $\begin{array}{l}\text { Peripheral } \\
\text { blood } \\
\text { F cell \% }\end{array}$ & $\begin{array}{c}\text { Burst } \\
\text { picograms } \\
\text { HbF/NRBC }\end{array}$ & $\begin{array}{c}\text { Peripheral blood } \\
\text { picograms } \\
\text { HbF/F Cell }\end{array}$ & $\begin{array}{c}\text { Burst } \\
\text { picograms } \\
\text { HbA/NRBC }\end{array}$ \\
\hline $1 \mathrm{a}$ & $40.8 \pm 6.0^{*}$ & - & $4.6 \pm 0.3$ & - & $21.8 \pm 1.9$ \\
\hline b & $43.7 \pm 5.0$ & - & $5.7 \pm 1.2$ & - & $22.3 \pm 3.2$ \\
\hline c & $52.8 \pm 7.0$ & $0.9 \pm 0.2$ & $4.8 \pm 0.4$ & $4.3 \pm 1.0$ & $23.0 \pm 5.0$ \\
\hline $2 \mathrm{a}$ & $49.8 \pm 12.1$ & - & $7.7 \pm 2.0$ & - & $30.4 \pm 1.8$ \\
\hline b & $51.1 \pm 6.0$ & $2.5 \pm 0.3$ & - & $4.2 \pm 1.2$ & - \\
\hline 3 & $32.9 \pm 8.1$ & $1.0 \pm 0.2$ & $4.8 \pm 0.5$ & $4.3 \pm 0.8$ & $24.0 \pm 3.0$ \\
\hline 4 & $11.9 \pm 2.8$ & $2.0 \pm 1.7$ & $5.1 \pm 1.6$ & $4.6 \pm 1.2$ & $29.1 \pm 4.0$ \\
\hline 5 & $30.1 \pm 4.7$ & $1.0 \pm 0.5$ & $4.0 \pm 0.8$ & - & $22.3 \pm 4.8$ \\
\hline 6 & $31.3 \pm 4.0$ & $6.3 \pm 0.7$ & $5.9 \pm 2.7$ & - & $35.1 \pm 3.9$ \\
\hline 7 & $24.4 \pm 3.5$ & $1.4 \pm 0.6$ & $4.1 \pm 1.0$ & $4.1 \pm 0.7$ & $26.4 \pm 4.2$ \\
\hline 8 & $44.0 \pm 2.7$ & $2.0 \pm 1.0$ & $5.4 \pm 3.0$ & - & $34.2 \pm 5.0$ \\
\hline 9 & $19.4 \pm 3.7$ & $3.4 \pm 0.5$ & $5.2 \pm 2.8$ & - & $29.4 \pm 3.8$ \\
\hline 10 & $24.0 \pm 4.2$ & $2.1 \pm 0.5$ & $4.8 \pm 1.5$ & - & $23.5 \pm 4.2$ \\
\hline 11 & $12.0 \pm 3.5$ & $2.0 \pm 1.0$ & - & - & - \\
\hline Mean \pm SE & $29.6 \pm 3.9$ & $2.2 \pm 0.5$ & $5.2 \pm 0.4$ & $4.3 \pm 0.1$ & $27.7 \pm 1.5$ \\
\hline
\end{tabular}

$*$ Mean \pm SD.

percentage of FNRBC per individual burst seems to be normally distributed between 5 and $95 \%$ (Fig. 1). This observation agrees with the broad normal distribution of the amount of $\mathrm{HbF}$ per burst previously reported by Kidoguchi et al. (4).

Aliquots from 22 of the 58 individual bursts analyzed in subject 1 were assayed for mean picograms $\mathrm{HbF} /$ NRBC and picograms HbA/NRBC (inset, Fig. 1). The

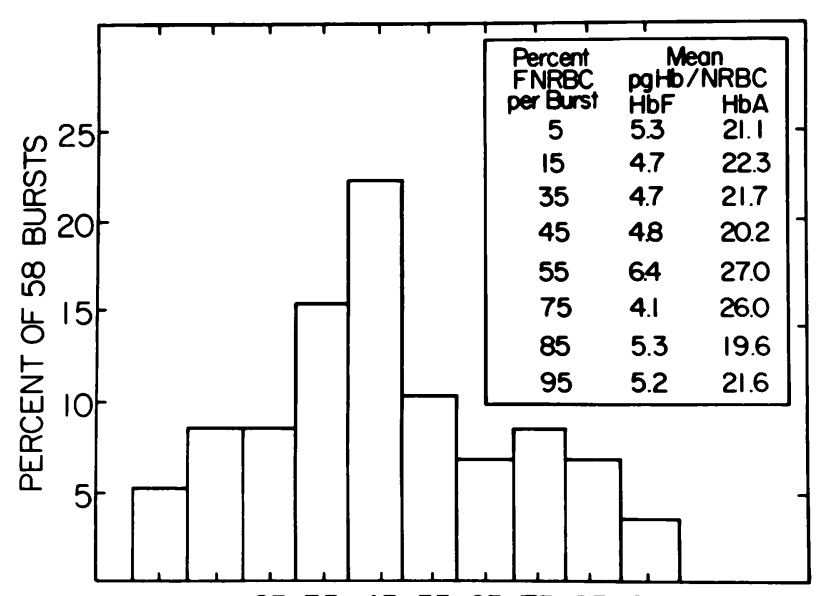

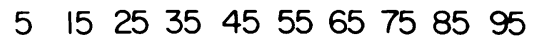
PERCENT FNRBC PER INDIVIDUAL BURSTS

FIGURE 1 Relative frequency of 58 individual bursts from a normal subject in relation to the percentage of FNRBC per individual burst. Inset represents mean picograms $\mathrm{HbF} / \mathrm{NRBC}$ and mean picograms HbA/NRBC for those bursts whose percentage of FNRBC are represented by the bars in the horizontal axis of the figure. Bursts are from subject 1 in Table I. average picograms $\mathrm{HbF} / \mathrm{NRBC}$ in individual bursts ranged from 4.1 to $7.6 \mathrm{pg}$ (mean $\pm \mathrm{SE}$ for 22 bursts is $5.0 \pm 0.2 \mathrm{pg}$ ). Just as noted in pooled burst analysis, there was no correlation between the mean picograms $\mathrm{HbF} / \mathrm{NRBC}$ and the percentage of FNRBC in individual bursts $(P=0.73)$. In addition, no correlation could be found in individual bursts between mean picograms $\mathrm{HbA} / \mathrm{NRBC}$ and either percentage of FNRBC $(P=0.57)$ or mean picograms $\mathrm{HbF} / \mathrm{NRBC}$ $(P=0.20)$. It therefore appears that neither the amount of $\mathrm{HbF} / \mathrm{NRBC}$ nor the percentage of FNRBC is a function of how much $\mathrm{HbA}$ is produced in individual bursts.

Subcolonies. Subcolonies from one burst were examined in two subjects (Table II). If commitment to the formation of $\mathrm{HbF}$ was complete before subcolony formation, we would have expected to see subcolonies with either no FNRBC or $100 \%$ FNRBC. However, all subcolonies contained some FNRBC and none had $100 \%$. In subject 8 a subcolony with $3.0 \%$ FNRBC and a subcolony with $81 \%$ FNRBC had essentially the same number of total cells (see legend, Table II). This observation excludes the possibility that the variation in the percentage of FNRBC among subcolonies is due to fusion of subcolonies containing no or $100 \%$ FNRBC. This, in turn, suggests that commitment to $\mathrm{HbF}$ production is ongoing throughout the life span of the burst.

\section{DISCUSSION}

In a previous report we noted that acquired elevation of $\mathrm{HbF}$ in vivo was a general phenomenon asso- 
TABLE II

Percent Nucleated Erythrocytes Containing HbF in Individual Subcolonies from a Single Burst in Each of Two Subjects

\begin{tabular}{cccc}
\hline Subject & $\begin{array}{c}\text { Percent } \\
\text { FNRBC/subcolony }\end{array}$ & Subject & $\begin{array}{c}\text { Percent } \\
\text { FNRBC/subcolony }\end{array}$ \\
\hline & $68.0 \pm 5.6$ & & $3.0 \pm 1.4^{*}$ \\
5 & $69.5 \pm 1.9$ & & $20.7 \pm 1.2$ \\
& $33.7 \pm 8.7$ & 8 & $22.0 \pm 3.7$ \\
& $52.4 \pm 4.2$ & & $51.8 \pm 3.9$ \\
& $29.3 \pm 8.3$ & & $81.0 \pm 3.6^{*}$ \\
& $35.3 \pm 0.5$ & & $33.0 \pm 1.4$ \\
& $49.3 \pm 7.1$ & & \\
\hline
\end{tabular}

* The subcolony with 3.0 and 81.0 percent FNRBC contained 209 and 190 total NRBC, respectively.

ciated with acute erythropoietic expansion (14). Increased F-cell number was uniformly associated with acute erythroid stimulation while the amount of $\mathrm{HbF} /$ cell did not necessarily change $(2,14)$. The present observations suggest that increased $\mathrm{HbF}$ production in culture is primarily due to a 6 - to 50 -fold increase in F-cell number while $\mathrm{HbF}$ and $\mathrm{HbA}$ per $\mathrm{NRBC}$ were equally increased by $\sim 20 \%$ over in vivo levels.

All bursts examined contained FNRBC in varying percentages. This finding agrees with isoelectric focusing of radiolabeled hemoglobin from individual bursts (4) but is discrepant from previously reported immunologic assays of $\mathrm{HbF}$ in single bursts $(5,6)$. These immunologic assays either analyzed aggregates of cells within a burst with fluorescent anti-HbF (5), or performed radioimmunoassays of lysate from individual bursts (6). It is possible that these techniques are not sensitive enough to detect $<5 \%$ FNRBC with only $4 \mathrm{pg} \mathrm{HbF} / \mathrm{NRBC}$ or that culture conditions vary significantly between laboratories.

Our results also differ somewhat from the finding of Papayannopoulou et al. (5) that the ability to produce $\mathrm{HbF}$ in culture is inversely related to the degree of differentiation of the erythroid precursor, i.e., $\mathrm{HbF}$ levels are higher in colonies derived from earlier erythroid progenitor vs. HbF level in colonies derived from late erythroid precursors (5). We find that the variation in the percentage of FNRBC between individual bursts from the same culture is similar to the variation in the percentage of FNRBC between subcolonies from a single burst. This suggests that commitment to $\mathrm{HbF}$ production is ongoing throughout the $14 \mathrm{~d}$ of burst formation and is not irrevocably programmed at a single early state of erythroid development.

\section{ACKNOWLEDGMENT}

This investigation was supported in part by National Institutes of Health grant HL20913 and the Veterans Administration.

\section{REFERENCES}

1. Papayannopoulou, T., M. Brice, and G. Stamatoyannopoulos. 1976. Stimulation of fetal hemoglobin synthesis in bone marrow cultures from adult individuals. Proc. Natl. Acad. Sci. U. S. A. 73: 2033-2037.

2. Dover, G. J., S. H. Boyer, and W. R. Bell. 1978. Microscopic method for assaying $\mathrm{F}$ cell production: illustrative changes during infancy and aplastic anemia. Blood. 52: 664-672.

3. Dover, G. J., S. H. Boyer, S. Charache, and K. Heintzelman. 1978. Individual variation in the production and survival of F cells in sickle cell disease. N. Engl. J. Med. 299: 1428-1435.

4. Kidoguchi, K., M. Ogawa, and J. D. Karam. 1979. Hemoglobin biosynthesis in individual erythropoietic bursts in culture. Studies of adult peripheral blood.J. Clin. Invest. 63: 804-806.

5. Papayannopoulou, T., T. Kalmantis, and G. Stamatoyannopoulos. 1979. Cellular regulation of hemoglobin switching: evidence for inverse relationship between fetal hemoglobin synthesis and degree of maturity of human erythroid cells. Proc. Natl. Acad. Sci. U. S. A. 76: 6420-6424.

6. Fauser, A. A., and H. A. Messner. 1979. Fetal hemoglobin mixed hemopoietic colonies (CFU-GEMM), erythroid bursts (BFU-E), and erythroid subcolonies (CFU-E): assessment by radioimmune assay and immunofluorescence. Blood. 54: 1384-1394.

7. Dover, G. J., and S. H. Boyer. 1980. Quantitation of hemoglobins within individual red cells: asynchronous biosynthesis of fetal and adult hemoglobin during erythroid maturation in normal subjects. Blood. 56: In press.

8. Ogawa, M., O. C., Grush, R. F. O'Dell, H. Hara, and M. D. MacEachern. 1977. Circulating erythropoietic precursors in culture: characterizations in normal men and patients with hemoglobinopathies. Blood. 50: 10811092.

9. Boyum, A. 1968. Isolation of mononuclear cells and granulocytes from human blood. Scand. J. Clin. Lab. Invest. 21(Suppl. 97): 77-89.

10. Iscove, N. N., F. Sieber, and K. H. Winterhalter. 1974. Erythroid colony formation in cultures of mouse and human bone marrow: analysis of the requirement for erythropoietin by gel filtration and affinity chromatography on agarose concanavalin A. J. Cell. Physiol. 83: 309-320.

11. Boyer, S. H., L. Margolet, M. L. Boyer, T. H. Huisman, W. A. Schroeder, W. G. Wood, D. J. Weatherall, J. B. Clegg, and R. Cartner. 1977. Inheritance of F cell frequency in heterocellular hereditary persistence of fetal hemoglobin: an example of allelic exclusion. Am. J. Hum. Genet. 29: 256-271.

12. Papayannopoulou, T., B. NaKamoto, J. Buckley, S. Kurachi, P. E. Nute, and G. Stamatoyannopoulos. 1978 Erythroid progenitors circulating in the blood of adult individuals produce fetal hemoglobin in culture. Science (Wash. D. C.). 199: 1349-1350.

13. Kidoguchi, K., M. Ogawa, J. D. Karam, and A. G. Martin. 1978. Augmentation of fetal hemoglobin (HbF) synthesis in culture by human erythropoietic precursors in the marrow and peripheral blood: studies in sickle cell anemia and non-hemoglobinopathic adults. Blood. 52: 1115-1124.

14. Dover, G. J., S. H. Boyer, and W. H. Zinkham. 1979. Production of erythrocytes that contain fetal hemoglobin in anemia. Transient in vivo changes. J. Clin. Invest. 63: $173-176$. 